\title{
UN EJEMPLO DE RENOVACIÓN PEDAGÓGICA EN CANARIAS DURANTE LOS AÑOS 30: TRAS EL RASTRO Y LOS RETOS DE LAS TÉCNICAS FREINET ${ }^{1}$
}

DOI: http://dx.doi.org/10.1590/2236-3459/64674

\author{
Manuel Ferraz Lorenzo
}

Universidad de La Laguna, España.

$\cos 80$

\begin{abstract}
Resumen
Aunque no podemos hablar de movimiento Freinet en Canarias durante el período de la II República, dado que no hubo un colectivo organizado y mínimamente unificado que hiciera realidad las técnicas propuestas por el pedagogo y maestro francés, sí podemos hablar de la existencia de docentes que, a título particular, conocían sus propuestas sobre el uso de la imprenta, el texto libre, la correspondencia escolar, la expresión libre y creativa, la organización cooperativa y asamblearia del aula, etc. y las intentaron aplicar a sus alumnos. De lo que ocurrió a este respecto, entre 1931 y 1939, trata el presente trabajo.

Palabras-clave: Islas Canarias, segunda república, renovación pedagógica, técnicas Freinet, Arturo Soriano.

\section{UM EXEMPLO DE RENOVAÇÃO PEDAGÓGICA NAS ILHAS CANÁRIAS DURANTE OS ANOS 30: SEGUINDO O RASTRO E DESAFIOS DAS TÉCNICAS FREINET}

\section{Resumo}

Embora não possamos falar do movimento Freinet nas Ilhas Canárias durante o período da Segunda República, devido a que não havia um grupo organizado e minimamente unificado que tornasse realidade as técnicas propostas pelo professor francês, podemos falar da existência de professores que, num âmbito particular, conheciam as propostas de Freinet sobre o uso da imprensa, texto livre, correspondência escolar, expressão livre e criativa, a organização cooperativa

\footnotetext{
${ }^{1}$ Deseo mostrar mi más sincera gratitud al profesor de la Unam, México, dr. Fernando Jiménez Mier Terán, eminente investigador sobre Freinet y la proyección de sus técnicas pedagógicas en España, por la lectura, revisión y sugerencias realizadas para mejorar el borrador inicial de este trabajo. Igualmente, quiero hacer extensiva la gratitud a Ana García Ruiz y a Diego Gómez Culebra. 
e parlamentar da sala de aula, etc. e tentaram aplicar aos seus alunos. O objetivo desse artigo é explicar o que aconteceu entre 1931 e 1939.

Palavras-chave: Ilhas Canárias, segunda república, renovação pedagógica, técnicas educacionais Freinet, Arturo Soriano.

\title{
AN EXAMPLE OF EDUCATIONAL RENEWAL IN THE CANARY ISLANDS DURING THE YEARS 30: FOLLOWING THE CLUE AND CHALLENGES OF THE FREINET'S TECHNIQUES
}

\begin{abstract}
Although we can't speak of Freinet movement in the Canary Islands during the period of the Second Republic, as there was not an organized and minimally unified collective to make reality the techniques proposed by the French teacher, we can speak of the existence of teachers, by themelves, knew Freinet proposals like the use of printing, free text, correspondence school, free and creative expression, and assembly cooperative classroom, etc. and they tried to apply to their students. What happened in this regard, since 1931 to 1939 , this work is.

Key-words: Canary Islands, second republic, educational reform, Freinet's technical, Arturo Soriano

\section{UN EXEMPLE DE RENOUVEAU PÉDAGOGIQUE DANS LES ÎLES CANARIES AU COURS DES ANNÉES 30: SUR LA PISTE ET DÉFIS DES TECHNIQUES FREINET}

\section{Résumé}

Bien que nous ne pouvons pas parler de mouvement Freinet dans les îles Canaries au cours de la période de la II République, car il n'y avait pas un groupe organisé et unifié pour faire réalité les techniques proposées par le pédagogue et professeur français, nous pouvons parler de l'existence d'enseignants qui en particulier, connaissaient leurs propositions sur l'utilisation de l'impression, le texte libre, l'école par correspondance, l'expression libre et créative, l'organisation de la classe coopérative et de réunion, etc. et ils ont essayé d'appliquer à leurs élèves. Ce qui est arrivé à cet égard, entre 1931 et 1939, ce travail est.

Mots-clé: Îles Canaries, deuxième république, le renouveau pédagogique, techniques Freinet, Arturo Soriano. 


\section{Maestros canarios conocedores de las prácticas educativas del freinetismo francés}

A I igual que ocurrió en el Estado español, cuyo difusor más destacado y precoz de las técnicas de la Escuela Moderna fue el maestro del Grupo Escolar Bailén
de Madrid, Sidonio Pintado Arroyo ${ }^{2}$, también en Canarias la primera referencia que tenemos de Freinet y de sus innovaciones pedagógicas parten de él ${ }^{3}$. Un artículo titulado La imprenta en la escuela, publicado previamente en la prestigiosa revista El Magisterio Español, era transcrito en Eco del Magisterio Canario y presentado a todos los docentes isleños en $1928^{4}$. En el mismo, se enaltecía la labor de la imprenta y de su impulsor, "nuestro querido amigo C. Freinet". Además, se comparaba lo realizado en otros centros privados, donde la imprenta sólo se utilizaba para relacionar la escuela con el hogar, con lo propuesto por Freinet "como base fundamental para la enseñanza de todas las materias escolares" y, se afirmaba, que "el pensamiento que anima esta nueva técnica, es totalmente original y de un gran interés educativo". En la parte final del trabajo que leyeron numerosos maestros canarios, pues la revista llegaba a muchos rincones de las Islas, se añadía:

La imprenta La lino ideada por nuestro amigo Freinet y extendida ya a numerosas Escuelas Francesas, viene a costar unos 400 francos. Tal vez sea un poco pronto para cantar las excelencias de este modernísimo procedimiento de enseñanza. Pero su extensión rápida y la recomendación que hemos oído a varios Inspectores primarios son una garantía. (Eco del Magisterio Canario, Santa Cruz de Tenerife. 7 sep. 1928)

Al parecer, esta narración incentivadora por parte de Sidonio de lo visto y descrito en una escuela renovadora francesa, no caló en la manera de pensar de los maestros canarios más preocupados por sortear los problemas surgidos en las aulas con ratios que sobrepasaban con creces los 50 alumnos, por disminuir el alto grado de absentismo en las zonas rurales y suburbiales, por dotar adecuadamente de materiales imprescindibles sus escuelas, por convencer sobre la necesidad de educar, además de enseñar, tanto a la población infantil como a sus progenitores y, sobre todo, por cobrar la gratificación de residencia como el resto de funcionarios del Estado que desempeñaba sus trabajos en las Islas. Sin embargo, tenemos constancia de algunos maestros que, si bien no compartieron las técnicas Freinet, al menos las conocían de alguna manera y se aproximaron mucho a

\footnotetext{
${ }^{2}$ No vamos a abordar el tema de manera general para la totalidad de España porque consideramos que ha sido ampliamente tratado por otros autores. Ante las numerosas publicaciones existentes, sólo vamos a citar las más representativas que investigan los planteamientos de Freinet en su dimensión histórica: (Blat, 1996), (Costa, 2010), (Colaboración, 1935-36), (Errico, 2014), (González-Monteagudo, 2013), (Hernández Díaz, y Hernández Huerta, 2007), (Hernández Huerta; Hernández Díaz, 2012), (Hernández Huerta, 2005). (Hernández Huerta, 2007), (Imbernón, 2009). (Jiménez, 1989), (Jiménez, 1994), (Jiménez, 1996), (Jiménez, 2011), (La imprenta, 1935), (Movimiento, 1979), (Ramos, 2016), (Zurriaga, 1979).

${ }^{3}$ Sidonio Pintado Arroyo, junto a Luis G. Bover Oliveras, Manuel J. Cluet Santiveri, Enrique Casassas Cantó, Antonio García Martín o el propio Herminio Almendros Ibáñez, serían los precursores de la Pedagogía Freinet en España.

${ }^{4}$ En el apartado de la revista titulado Iniciativas pedagógicas se insertaba el trabajo que fue publicado en la edición del 7 de septiembre de 1928. El original de la revista El Magisterio Español, estaba fechado el 15 de agosto del mismo año. No debemos confundirlo con el publicado por el mismo autor, con el mismo título y en la misma revista dos años antes, esto es, el 8 de noviembre de 1926. Aunque aparecen algunos párrafos distintos, se exponen ideas y argumentos complementarios. A este respecto ver Jiménez (2011, p. 131-137). Hist. Educ. (Online) Porto Alegre v. 20 n. 50 Set./dez., 2016 p. $157-175$
} 
ellas. En este grupo debemos hacer referencia a los maestros rurales Julián B. Caparrós Morata y Luis Diego Cuscoy (Ferraz y González, 2016), (Clavijo, Ferraz y Navarro, 2009), (Ferraz, 2011).

El primero de ellos, Julián Caparrós Morata, nació en Vera, Almería, el 9 de enero de 1908. De padres muy humildes -su padre, Pedro Caparrós Caparrós, era jornalero y su madre, María Morata Sirvente, se dedicaba a las labores domésticas-, quedó huérfano de su progenitor desde muy pequeño. Pese a todo, como hijo único pudo realizar los estudios de magisterio en Valencia bajo la protección de su tío, clérigo de aquella diócesis, quien le costeó todos sus gastos. Aunque desconocemos buena parte de su etapa juvenil, sí podemos confirmar que estudió magisterio en la Escuela Normal de Maestros de Valencia y que terminó en septiembre de 1928. Una vez aprobadas las oposiciones ese mismo año, llegó a Canarias donde tuvo el primer nombramiento el 7 de noviembre de 1930: primero, como maestro propietario de la escuela unitaria de niños de Caideros en Gáldar, Gran Canaria, y el curso siguiente en la escuela nacional de niños de Valle de Guerra, en La Laguna, Tenerife ${ }^{5}$.

En 1933 se traslada, junto a su esposa, a Santa Lucía de Tirajana, Gran Canaria, donde los dos ocupan sendas plazas de docentes en las escuelas públicas de dicha localidad. Durante aquellos años, y pese a la militancia comunista de Julián, se convierten en defensores de las reformas educativas auspiciadas y patrocinadas por los gobiernos republicanos más progresistas. Tras el pronunciamiento militar fue severamente depurado y represaliado por los golpistas, hasta ser separado definitivamente de las aulas ${ }^{6}$.

De él disponemos de una leve referencia en la que, en carta remitida a su amigo Ferrán Zurriaga entrados ya los años 70 del siglo pasado, y tras expresarle la decepción que sentía del trabajo realizado por parte de los maestros actuales, le transmitía: "Recuerdo cómo puse en marcha una modesta cooperativa de material pedagógico allá por los años 30 , cuando el presupuesto de material escolar no llegaba a las ciento cincuenta pesetas netas [...] Había una ética que hoy no existe" ${ }^{\text {" }}$. Aunque sabemos que con la llegada de la democracia no se adhirió al colectivo que trabajaba las Técnicas Freinet en España, especialmente en Valencia, es más que probable que durante la II República las conociera y se sintiera atraído por ellas, si bien no disponemos de más información al respecto que nos permita integrarlo dentro del grupo de maestros freinetianos. Sí sabemos que entabló relación con Célestin Freinet y con su equipo de trabajo francés durante los años 60 (con quienes, según todo los indicios, se carteaba), con Herminio Almendros, al que llegó a visitar durante su estancia en Cuba, con Gaston Mialaret, a quien le unió la formación y la pasión por las matemáticas; con José Blat Jimeno, delegado de la Unesco en el Hemisferio Occidental, etc. Pero eso no nos permite vincularlo a las técnicas Freinet durante los años republicanos.

Podemos constatar, además, su perseverancia educativa y su malestar ante el modelo formador de los maestros y la escasa actitud vocacional que tenían; una de sus críticas principales la dirigía a la Escuela Normal. "Hay que comenzar por el principio. Y el principio no tiene vuelta de hoja: carecemos del maestro que necesita nuestra coyuntura

\footnotetext{
${ }^{5}$ Hoja de servicio. Expediente personal de Julián B. Caparrós Morata. Archivo de la Consejería de Educación. Gobierno de Canarias. Las Palmas de Gran Canaria.

${ }^{6}$ Expediente personal de Julián Caparrós Morata. Archivo Histórico Provincial de Las Palmas, Gobierno civil, orden público.

${ }^{7}$ Carta enviada por Julián B. Caparrós Morata a Ferrán Zurriaga, el 18 de enero de 1978. \begin{tabular}{|l|l|l|l|l} 
Hist. Educ. (Online) & Porto Alegre & v. 20 & n. 50 & Set./dez., 2016
\end{tabular}

p. $157-175$
} 
histórica. Lo que ha estado lanzando la Normal en estos últimos tiempos es una mercancía averiada. Salvo muy honrosas excepciones, yo no descubro al maestro que nuestros tiempos reclama" ${ }^{8}$. Y algunos meses más tarde, enfatizaba: "Para mí, el punto de arranque que pudiera llevarnos con pies seguros a un nivel mínimo de positividades está en la calificación técnica y política de nuestro magisterio". E insistía en otra de sus misivas: "para mí el problema número uno es muy concreto: buscar una solución para que el maestro lea, y lea textos valiosos"9, entre los que sugería los de Célestin Freinet y Herminio Almendros.

En su colaboración internacional, formó parte del Groupe International D'Estudes pour L'Apprentissage des Mathematiques - Gieam -, de la International Study Group for Mathematics Learning -ISGML-, de la Asociación Internacional de Educadores por la Paz Mundial - IAEWP - o de la Association for Teacher Education in Europe -Atte-, además de convertirse en un claro defensor y propagador del aprendizaje de las matemáticas según el método de Zoltan Dienes. Fueron los últimos compromisos que adquirió, porque el 28 de mayo de 1988 moría en la ciudad de Las Palmas.

Con respecto a Luis Diego Cuscoy (Girona, 1907; Tenerife, 1987), tampoco podemos constatar que empleara periódicos escolares en sus clases, ni textos libres en el aula que condujeran a crear el libro de la vida, ni ficheros autocorrectivos, ni bibliotecas de trabajo, ni siquiera correspondencia con otros escolares. En sus escritos no aparecen referencias precisas a estas prácticas escolares tan emblemáticas de la pedagogía freinetista. Quizás los destinos escolares que ocupó en zonas extremadamente pobres, agrarias e incultas dificultara la realización de estas experiencias para las cuales se precisaban, al menos, ciertas habilidades lecto-escritoras que la mayoría de sus alumnos -en sus masificadas clases- desconocían por completo. Entonces, ¿qué es lo que nos lleva a vincularlo a la Pedagogía Freinet? Además de todas sus teorizaciones pedagógicas, que vistas in extenso son parte esencial del binomio vida y escuela de la Escuela Moderna, hay un dato que queremos resaltar.

En 1933 se le premió y publicó el trabajo titulado Ensayo de lectura consciente en una escuela rural en la Revista de Pedagogía, que también vio la luz en la prensa de Canarias (Diego, 1933a); lo que nos sorprende es que simultáneamente este mismo artículo fue traducido al francés y publicado en una de las más importantes revistas del momento en cuanto a renovación pedagógica se refiere y, además, órgano de difusión de la Escuela Moderna francesa bajo los auspicios directos de Célestin Freinet: nos referimos a L'éducateur Prolétarien.

Esta revista comenzó su andadura en octubre de 1932 con una periodicidad mensual, para pasar a tener dos años más tarde una tirada quincenal, hasta finalizar su actividad en julio de 1939, fecha en que pasó a denominarse solo L'éducateur por motivos relacionados con la censura militar; pues bien, en su número 8 correspondiente al mes de mayo de 1933, junto a trabajos de Freinet, Pichot, Lina Darche, G. Vovelle, Manuel-F. Cluet, M. et S. Lallemand, J. Lagier-Bruno, etc. se publicaba, bajo el encabezado de Nos recherches pédagogiques: l'amour de la lecture chez l'enfant, el trabajo de Luis Diego Cuscoy con una variante en su título: Un ensayo de lectura consciente de una escuela rural española (Diego, 1933b). El proyecto escolar que había salido de una de las más deprimidas zonas de Galicia - advirtamos que durante dos cursos escolares estuvo destinado como maestro

${ }^{8}$ Carta enviada a Ferrán Zurriaga en 1978, pero sin fecha concreta.

${ }^{9}$ Carta enviada a Ferrán Zurriaga, el 6 de junio de 1978. Hist. Educ. (Online) Porto Alegre v. 20 ก. 50 Set./dez., 2016 p. $157-175$ 
allí -, y cuya vocación había sido la de estimular la lectura de adolescentes que apenas sabían las primeras letras -comparables e intercambiables, por cierto, a los alumnos que había conocido y que volvería a encontrar en las escuelas rurales canarias- , se presentaba en Francia como un intento de renovación pedagógica española, educativamente factible y exportable para su conocimiento a Europa, bajo el paraguas igualador y comprometido de la Escuela Moderna y de todo lo que ella -en momentos de euforia no exenta de precariedad educativa- suponía. Esta suerte de proyectos y de realizaciones nos impelen a plantear algunos interrogantes para los que actualmente no tenemos respuestas: ¿Quién apoyó este trabajo para que se publicara en Francia con el aval incondicional de Célestin Freinet?, ¿fue suficiente garantía haberlo publicado en la Revista de Pedagogía?, ¿por qué otros trabajos de reconocida valía publicados en la revista española no fueron traducidos y publicados en la revista francesa?

Es cierto que no hubo más contribuciones de Diego Cuscoy en esta revista, ni en ninguno de los 15 números de su homóloga española Colaboración, la Imprenta en la Escuela, Boletín de la Cooperativa española de la técnica Freinet, que se publicó entre marzo de 1935 y junio-julio de $1936^{10}$; también es cierto que sus manuales escolares echan por tierra la idea del texto libre y del libro de la vida aunque, objetivamente, poco importa este dato dado que ambos textos fueron escritos y publicados en los años 40 cuando los docentes freinetianos habían sido depurados y sus técnicas ferozmente perseguidas.

Sí debemos de comprender, sin embargo, que durante el período de máximo esplendor de estas prácticas, Diego Cuscoy estaba en Tenerife completamente aislado y abstraído de las modernas teorizaciones educativas y de los congresos y seminarios realizados a tal efecto, enseñando a leer y escribir a los niños de la zona agrícola de El Sauzal y participando activamente en La Prensa con trabajos como Crónicas para la prensa. Guerra... niños, El por qué de las escuelas sin niños, o en Trabajadores de la enseñanza con el artículo premonitorio de la guerra civil titulado Pueblos y maestros frente a la guerra. En este sentido, nos embarga la incertidumbre de no poder ubicarlo dentro de dichas prácticas, pero, del mismo modo, tampoco podemos dejarlo fuera del todo sin una investigación más minuciosa y exhaustiva sobre sus posibles contactos pedagógicos en la Península, que su correspondencia no termina de esclarecer. En toda esta maraña hay algo que podemos constatar y es su conocimiento de la Escuela Moderna y de las técnicas educativas que la caracterizaron, pues uno de sus libros de cabecera fue La imprenta en la escuela: la técnica Freinet, de Herminio Almendros, que había visto la luz en 1932 gracias a las publicaciones de la Revista de Pedagogía y que adquirió poco después para su biblioteca particular.

\footnotetext{
${ }^{10}$ Para un mayor conocimiento de la importancia que adquirió esta revista en el panorama de la renovación educativa española durante los años finales de la República, véase Jiménez, 1996. 


\section{Reveladores ejemplos de periódicos escolares en Canarias y su persecución por los sectores más conservadores de la población}

Una de las experiencias más importantes, en este sentido, tuvo lugar a partir de la inauguración del Grupo Escolar Graduado de Niños Duggi, en Santa Cruz de Tenerife, el 27 de octubre de $1932^{11}$. A partir de este momento, y en su 12 secciones consideradas a todas ínfulas como 12 escuelas, se intentó hacer realidad el sueño de la renovación educativa que con tanto ahínco se defendía por parte de la prensa de derechas y de izquierdas, sin concretar muy bien en qué consistía más allá de la lógica demanda de la escolarización generalizada y de la erradicación del analfabetismo.

Aunque en febrero de 1933 continuaban vacías más de la mitad de sus aulas, 7 en concreto, a partir de mayo del mismo año el Grupo Escolar comenzó con sus actividades educativas y para-educativas de todo tipo: se hizo cargo de organizar los cursillos de perfeccionamiento de los maestros rurales en su afán por extender la renovación pedagógica y la higiene infantil a todos los rincones de las islas; también se realizaron en él las oposiciones a directores de colegios; ciclos de conferencias; exposiciones de todo tipo; se creó un equipo de fútbol infantil; se proyectaron películas para contribuir pedagógicamente al aprendizaje de los alumnos; destacó públicamente por la defensa de los derechos de los niños, etc.

Sin embargo, lo que nos interesa resaltar es que, bajo la dirección de Francisco de Vega Barrera ${ }^{12}$, y con el compromiso asumido por el resto de maestros y del inspector de la zona, Julián Sánchez Vázquez, los niños del centro escolar elaboraron un periódico mensual que sobresalía por la originalidad de sus textos y dibujos. Una iniciativa que fue comentada por los periódicos locales de la época y que elogiaron sin ningún tipo de prejuicios ideológicos. Tanto Gaceta de Tenerife, diario de derechas, como La Prensa, diario independiente, u Hoy, diario republicano se hacían eco de la noticia en términos muy encomiables. El primero, con el título de Grato recibo. El Infantil Duggi, manifestaba lo siguiente:

A las mesas de nuestra Redacción ha llegado un nuevo periódico: "El Infantil Duggi", que mensualmente se edita en el Grupo Escolar del barrio Duggi en esta capital. Es notable por los interesantes dibujos cuidadosamente confeccionados por alumnas y alumnos del Grupo. Los textos son un "tesoro

\footnotetext{
${ }^{11}$ Así se exponía el hecho por parte de la prensa insular: "Ábranse escuelas y más escuelas en esta capital y hasta en los más modestos lugarejos de nuestra provincia, dotadas todas con los elementos de la moderna Pedagogía. Que si tenemos anhelos cotidianos de engrandecimientos materiales $y$ de esplendideces de nuestra riqueza turística, por sobre esta aspiración isleña es necesario que prevalezca el esfuerzo para ir formando generaciones sin la mácula depresiva del analfabetismo". Gaceta de Tenerife. Diario Católico. Órgano de las Derechas. 30 de octubre de 1932. El ejemplar del 28 de octubre también recogía amplia información sobre la inauguración.

${ }^{12}$ Francisco de Vega Barrera era una autoridad en el sentido académico del término. Además de ser el respetado director del mencionado Grupo Escolar, era el maestro referente de los alumnos de la Escuela Normal de Magisterio cuya presencia y contacto eran evocados continuamente como ejemplo a seguir. Habría que añadir a ello, que se convirtió en el responsable -por delegación de la inspectora-jefe Susana Villavicencio Pérez- de visitar las Islas de El Hierro y la Gomera para girar visitas a los maestros que solicitaban hacer las pruebas para su ascenso en el escalafón profesional. Por último, tenía también entre sus cometidos el de presidir las comisiones calificadoras destinadas a conceder los certificados de estudios primarios, para lo cual viajaba por todas las islas de la provincia. No es de extrañar que por sus cualidades y compromisos educativos adquiridos, la prensa lo considerara "uno de los más destacados y positivos valores del magisterio de Tenerife". Hoy. Diario Republicano, Santa Cruz de Tenerife. 1 de abril de 1933. La misma noticia era recogida por Gaceta de Tenerife, Diario católico, Órgano de las derechas. 7 de septiembre de 1934.
} 
de espontaneidad nutrido en las mismas fuentes de la vida". El extraordinario tirado con motivo de la Fiesta de la Raza, es de lo más aleccionador, contiene datos preciosos. Enhorabuena a maestras, maestros y alumnos del Grupo Duggi que saben ponerse a tono con las nuevas corrientes pedagógicas, marcando la ruta a seguir en los demás centros de Enseñanza. Seguros estamos que han de encontrar alientos y apoyo en aquellas personas que de alguna manera están obligadas a interesarse por las cuestiones pedagógicas en nuestro país. (Gaceta de Tenerife, Diario católico, Órgano de las derechas. 12 de octubre de 1935)

En términos parecidos se expresaba La Prensa. Con el título Un periódico escolar editado por el Grupo Duggi, se afirmaba:

Ayer tuvimos el gusto de recibir en esta Redacción un ejemplar de la publicación mensual del Grupo escolar del barrio de Duggi, que se denomina "El Infantil Duggi". También recibimos un extraordinario de la misma publicación, dedicado a la fiesta de la Raza. Se trata de una revista, de carácter escolar, en la que colaboran los maestros y los niños de aquel Grupo. Está editada en máquina multicopista con gran limpieza e ilustrada con multitud de dibujos de los mismos niños. Es un trabajo sumamente curioso, que revela el entusiasmo profesional de los maestros y la buena orientación pedagógica que se da a los escolares. Por ello felicitamos efusivamente al profesorado, y especialmente al director don Francisco de Vega, y a los niños que a tan temprana edad realizan trabajos de mérito. ( $L a$ Prensa, Diario de la mañana. Santa Cruz de Tenerife. 12 oct., 1935)

El tercero, titulaba la nota de prensa El Infantil Duggi en nuestra casa y añadía: "Hemos recibido la revista 'El Infantil Duggi'. Publicación mensual del Grupo Escolar del barrio Duggi. Es tan interesante la citada revistas y está tan bien hecha, que prometemos ocuparnos de ella más adelante" (Hoy. Diario Republicano, Santa Cruz de Tenerife. 6 de diciembre de 1935); en este caso se refería al número 3 que correspondía al mes de diciembre. El número 4 era anunciado por La Prensa a través de la siguiente semblanza:

Hemos recibido el cuarto número del periódico escolar "Infantil Duggi." Este
número consta de ocho páginas, confeccionadas por los alumnos del citado
grupo escolar, además de un suplemento gráfico. Está profusamente
ilustrado y demuestra el perfeccionamiento que los simpáticos escolares
han adquirido en el arte periodístico. Nuestra enhorabuena a los inteligentes
alumnos y a su entusiasta profesor. (La Prensa, Diario de la mañana. Santa
Cruz de Tenerife. 17 ene., 1936)

Sabemos que se publicaron 5 ejemplares, tal y como recogió en una de sus ediciones de febrero La Gaceta de Tenerife ${ }^{13}$. "Hemos recibido el número 5 del Infantil Duggi donde los pequeños artistas del grupo escolar de dicho barrio archivan las filigranas de su precoz ingenio", pero no tenemos constancia de ninguna otra tirada; al menos la prensa de la época no da cuenta de que se publicaran más ejemplares. Aunque no hayamos podido encontrar ni rastro de la revista, los comentarios realizados de la misma revelan la extraordinaria originalidad de sus contenidos y la elaboración personal y entrega total efectuadas por parte de los alumnos.

${ }^{13}$ Gaceta de Tenerife, Diario católico, órgano de las derechas. 6 de febrero de 1936. \begin{tabular}{|l|l|l|l|l|l|}
\hline Hist. Educ. (Online) & Porto Alegre & v. 20 & n. 50 & Set./dez., 2016 & p. 157-175
\end{tabular} 
Muy parecida fue la experiencia ocurrida también en la Escuela Graduada Anexa a la Normal de La Laguna. Según se desprende de las noticias periodísticas que hemos podido recopilar, un grupo de niños y de niñas se dispusieron a fundar una biblioteca y a editar un periódico escolar. Para poner en marcha la primera de las iniciativas, solicitaron el concurso de la población en general y, especialmente, la solidaridad de

los niños ricos, que si están suscritos a revistas infantiles, tales como Gente Menuda, María Luz, Pocholo, Rintintín, etc., así como otras revistas ilustradas, Campeón, Algo, Crónica, etc., se acuerden de que a los niños pobres nos gusta leerlas y distraernos, y por ello pedimos se acuerden de nosotros y nos las remitan una vez que las hayan leído. (Gaceta de Tenerife, Diario católico, Órgano de las derechas. Santa Cruz de Tenerife. 10 nov., 1934; y La Prensa, Diario de la mañana. Santa Cruz de Tenerife. 10 nov., 1934).

Con respecto a la segunda propuesta, se afirmaba que

para nuestro periódico, la Junta directiva del mismo que será elegida hoy sábado, día 10 del actual mes de Noviembre, y la cual la formarán niñas y niños de todos los grados, deseamos suscriptores. No pedimos precio alguno; los que deseen recibir el periódico nos lo avisarán para mandárselo; dándonos para cada número lo que cada cual quiera. (Gaceta de Tenerife, Diario católico, Órgano de las derechas. Santa Cruz de Tenerife. 10 de nov., 1934; y La Prensa, Diario de la mañana, Santa Cruz de Tenerife. 10 nov., 1934)

Por lo que se desprende de lo publicado, a toda luces redactado por los propios alumnos, no parece que fuera un periódico escolar para intercambiar exclusivamente con otros compañeros; sí se sobreentiende, sin embargo, que era elaborado por los niños para dar a conocer sus iniciativas previamente desarrolladas en el centro escolar ${ }^{14}$.

En esta línea de análisis, no podemos constatar que ninguna de estas dos iniciativas -ni otras que tuvieron lugar en el resto del Archipiélago- formaran parte de la actividad freinetiana de la imprenta en la escuela, ni siquiera sabemos si realmente hubo intercambio de estas publicaciones con las editadas por otros centros educativos de las Islas o de fuera de ellas; pero el mero hallazgo de su existencia, nos sitúa en una corriente de pensamiento pedagógicamente renovadora y socialmente aperturista muy próxima a las técnicas y a los postulados defendidos por Freinet ${ }^{15}$.

${ }^{14}$ Gaceta de Tenerife, Diario católico, Órgano de las derechas. 10 de noviembre de 1934; La Prensa, Diario de la mañana. Santa Cruz de Tenerife, 10 de noviembre de 1934; y Hoy, Diario Republicano. Santa Cruz de Tenerife. 11 de noviembre de 1934. La carta que llevaba por encabezado "Proyecto Escolar. ¡Al público!” la escribía la niña Rosa Elvira Fernaud en nombre de todas las niñas y niños de la Escuela Graduada anexa a la Normal de La Laguna. Pero de dichas iniciativas no se supo nada más; ni siquiera en el diario Hoy, que ofrecía una página infantil dominical "para que den cuenta en ella de sus actividades escolares", apareció nota alguna referida a dichos proyectos educativo-culturales.

${ }^{15}$ Respecto a estas experiencias periodísticas, debemos de tener en cuenta los siguientes comentarios realizados por el profesor Fernando Jiménez: "Considero oportuno señalar que el mérito de Célestin Freinet no es trasladar la imprenta a la escuela. Ese incidente es muy anterior. La importancia del freinetismo reside en llevar a la escuela un proyecto educativo muy profundo y a la vez muy sencillo: darle definitivamente la palabra al niño para que se exprese libremente. La imprenta Freinet surge para eso, sirve apara que el crío confeccione sus textos libres, sus cuadernos escolares y sus libros de Vida". (Jiménez, 2011, p. 190). Dudamos mucho que en los dos ejemplos referidos a la Isla de Tenerife, se concediera tanta libertad de expresión a los alumnos como para confeccionar textos libres, cuadernos escolares y libros de Vida, al modo freinetiano. 
De lo que sí estamos seguros, y lo podemos constatar documentalmente, es de que propuestas como éstas fueron radicalmente combatidas por aquellos sectores ideológicamente más conservadores vinculados a la iglesia católica. En una época de tantos contrastes en el terreno político y en las restantes dimensiones sociales, no todos estaban de acuerdo con estas experiencias educativas. Que los alumnos elaboraran periódicos a través de su propia iniciativa, que la libertad de expresión campara a sus anchas en las escuelas con el visto bueno de los maestros, que los niños dispusieran de su espontaneidad y creatividad e hicieran partícipes de ellas a sus iguales, no era oportuno para los intereses de quienes consideraban que los hijos eran mera propiedad -con derecho adquirido y no transferible- de sus padres. Hay infinidad de ejemplos que aluden a ello, pero sólo nos vamos a detener en dos casos que sobresalen por su trascendencia en esta concepción reaccionaria de la educación.

En primer lugar, ante el temor de perder el control social, y el supuesto control paternal, cualquier acusación servía para desacreditar las reformas del gobierno republicano y las innovaciones docentes propuestas sin reparar en las virtudes pedagógicas de las mismas. Si el Estado imponía un determinado modelo de enseñanza era porque -argüían estos sectores ultraconservadores- suplantaba la voluntad que tenían los padres de elegir la educación que preferían para sus hijos; si eran los maestros los que innovaban en sus clases y permitían el desarrollo intuitivo de sus alumnos, se consideraba una irresponsabilidad intolerable y una falta de libertad ante el modelo de enseñanza elegido: “¿De quiénes son los niños? Los niños no son del Estado. Son en primer lugar de sus padres a quienes se los ha dado Dios para que los eduquen"16, o “iNuestros hijos son nuestros y no del Estado! ¡Viva la libertad de enseñanza! ${ }^{17}$, era el lema habitual abanderado en sus órganos de expresión para demostrar que los niños no poseían autonomía para tomar sus propias decisiones (ni siquiera sus maestros).

Por otra parte, y en segundo lugar, uno de los principales instigadores de estas propuestas había sido Enrique Herrera Oria, jesuita español, máximo ideólogo del franquismo y principal teorizador de las tendencias ultras y fascistas desde los tiempos de la II República. Fue él quien escribió una especie de catecismo espiritual pro-franquista titulado España es mi madre, publicado durante la Guerra civil, donde reducía todos los males de la patria a la influencia de la Institución Libre de Enseñanza, a las nuevas corrientes pedagógicas de la Escuela Nueva, a la masonería y a las conspiraciones del Judaísmo. Pues bien, fue este mismo hombre el que durante unas conferencias celebras en 1935 en las Islas de Gran Canaria, Tenerife y La Palma, arremetió contra el modelo de Escuela Moderna y todo lo que ella suponía para la libertad del niño en contra de la libertad suprema, y sagrada, de sus progenitores ${ }^{18}$. Con la colaboración de la Asociación de Padres de Familia (católicos) de las distinta Islas, se encargó de frenar las incipientes tendencias educativas de carácter renovador. Estas dos fórmulas de propaganda, entre otras muchas, fueron las elegidas en el Archipiélago para desgastar la enorme variedad de propuestas

\footnotetext{
${ }^{16}$ Acción Social, Religión, Patria, Familia, Orden, Trabajo y Propiedad. Santa Cruz de La Palma, 31 de mayo de 1933.

17 Acción Social, Religión, Patria, Familia, Orden, Trabajo y Propiedad. Santa Cruz de La Palma, 1 de julio de 1933.

${ }^{18}$ Gaceta de Tenerife, Diario católico, Órgano de las derechas. 2 de enero de 1935. \begin{tabular}{|l|l|l|l|l|l|}
\hline Hist. Educ. (Online) & Porto Alegre & v. 20 & n. 50 & Set./dez., 2016 & p. 157-175
\end{tabular}
} 
que, desde todos los rincones, abogaban por escolarizar a los niños y estimularles el aprendizaje desde sus propias experiencias personales y teniendo en cuenta las corrientes pedagógicas innovadoras en boga.

Intentar la renovación pedagógica en aquellas condiciones fue difícil, no intentarlo habría sido un fracaso estrepitoso en el ámbito más general de la regeneración social y del aperturismo cultural. De hecho, entrados los años 30, nos encontramos con una importante referencia en la revista L'éducateur Prolétarien, en la que un maestro de la tercera sección de la escuela nacional de Agüimes, y otro del tercer grado de la escuela número dos de Adeje, escribieron a los maestros freinetistas franceses para solicitar información sobre el intercambio de correspondencia escolar. Según manifestaban, estaban dispuestos a realizarla tanto en español como en esperanto ${ }^{19}$.

Como podemos comprobar, había información en Canarias sobre estas prácticas, contactos establecidos con quienes las cultivaban, e interés en experimentarlas y desarrollarlas. Pues bien, esto fue lo que se propusieron, con los modestos medios disponibles a su alcance, maestros como Agustín Sandoval Mulleras, que desempeñó su docencia en Adeje, sur de Tenerife; Arturo Soriano García, en Agüimes, Gran Canaria, y, probablemente también, José Manuel Conesa Cazorla, en Marzagán, Gran Canaria, y Guillermina Santana Aldama, en La Pardilla -Telde-, Gran Canaria , además de algunos otros de los que desconocemos sus nombres. Ninguno de ellos se dejaron amilanar por las consignas de carácter reaccionario y defendieron en sus clases las modernas metodologías docentes; en concreto, aspectos muy vinculados a las técnicas Freinet, que implantaron de manera arriesgada, personalizada y vanguardista. Detengámonos, como botón de muestra, en la figura de este último por ser el maestro del que más referencia documentales hemos podido disponer, a la espera de continuar en breve la investigación de los restantes.

\section{La labor docente y el compromiso cultural adquirido por Arturo Soriano García}

Uno de los maestros más identificados con el freinetismo, que impartieron su docencia en Canarias, nació en San Vicente de la Barquera, Cantabria, el 29 de mayo de 1899. Cursó sus estudios de magisterio en Madrid y aprobó las oposiciones al cuerpo de maestros de enseñanza primaria en 1925.

A partir de entonces, su prioridad consistió en dedicarse a la docencia "convencido de que el éxito en el buen funcionamiento de una escuela dependía, de manera exclusiva, de la cordial entrega del Maestro, y de que las deficiencias en los medios didácticos solían ser más ilusorias que reales" ${ }^{20}$. Su primer destino tuvo lugar en la escuela mixta de Tudes-Tollo-Vega de Liébana, Cantabria, población rural donde, según afirmaba desconsolado, los niños y niñas asistían a la misma siempre que sus ocupaciones agrícolas se lo permitían.

Debido a motivos profesionales y, sobre todo, personales, el 1 de mayo de 1929 comienza a dar sus clases en Canarias, concretamente en la sección $3^{a}$ de la Escuela Nacional Graduada de Agüimes, en Las Palmas de Gran Canaria, dato que coincide con el

\footnotetext{
${ }^{19}$ La revista recogió dicha información, junto a la de otras escuelas españolas, en el ejemplar de mayo de 1933, n. 8, sección Qui leur répondra?, p. 441. Debemos recordar que esta petición tuvo lugar antes, incluso, del surgimiento de la Cooperativa española de la técnica Freinet, lo que da cuenta del conocimiento y motivación mostradas por algunos docentes canarios para trabajar siguiendo estas pautas pedagógicas.

20 Apuntes extraídos de una Memoria Personal redactada y documentada por el propio Arturo Soriano García, p. 2. Archivo particular de su hijo Antonio Soriano Rodríguez, a quien desde estas páginas queremos agradecer la amabilidad y la colaboración prestada en el desarrollo de este trabajo.
} 
referido anteriormente en la revista L'éducateur Prolétarien, donde llega en calidad de director y se encuentra de manera imprevista con lo que el propio Soriano calificaría de verdadero desastre. Apenas un año después, y debido a sus gestiones y a la colaboración de dos jóvenes compañeros de profesión, aquella primera impresión cambió notablemente: "El ambiente se hizo propicio a fuerza de tesón y una escuela destartalada, desprovista del material indispensable, subestimada por autoridades y vecindario, se transformó en una escuela alegre, repleta de matrícula y asistida del cariño del pueblo y la ayuda moral y material del Municipio" (Memoria personal, Arturo Soriano García, p. 3).

En dicho lugar trabajó durante la recta final de la dictadura primorriverista y el período republicano, esto es, desde 1929 hasta $1936^{21}$. Allí estableció e impulsó la dotación de una biblioteca escolar con cientos de volúmenes donados por el Museo Pedagógico, el Ministerio de Instrucción Pública y Bellas Artes, y el propio Consistorio municipal; incluso, de su peculio particular se suscribió a la Compañía Iberoamericana de Publicaciones para recibir las mejores obras de literatura y ponerlas a disposición de todos los escolares. En esta línea de cambio profundo propiciada por el gobierno republicano, también renovó el material escolar y adquirió laboratorios a través de convenios realizados con el Ministerio; igualmente, fundó una Cooperativa Pedagógica integrada por maestros de distintas zonas con el objetivo de adquirir el material científico necesario para la adecuada formación de los niños en disciplinas como Física, Química, etc.

El citado material rotaba solidariamente por las distintas escuelas cada 15 días. En las clases de adultos, de manera prioritaria aunque no exclusiva, destinó una hora todos los sábados para que aquellas personas más destacadas por sus conocimientos de todo tipo tanto del pueblo como de fuera de él -, pudieran impartir conferencias y dialogar con los alumnos para ampliar, de este modo, el carácter del aprendizaje desde una vertiente no formal; aplicaba así su lema de que "la actividad del Maestro no debe limitarse a su labor intraescolar" (Memoria personal, p. 5). Además de todo lo expuesto, y ante la carencia de centros de enseñanza secundaria en la localidad, se dedicó a dar clases de Bachillerato y de Magisterio, fomentando, según su propio testimonio, la igualdad de oportunidades y, para contribuir a ello, sin cobrar a los alumnos económicamente más desfavorecidos. Podríamos seguir enumerando una lista casi interminable de actividades a las que dedicó todo su tiempo como, por ejemplo, la organización de fiestas escolares entre distintos centros para acercar de este modo a los alumnos, o los paseos y juegos al aire libre "para estudiar a los niños en ese ambiente de espontaneidad".

Pero si hay algo que queremos resaltar, son dos aspectos que introdujo como novedad en la educación impartida en Canarias y que echaban por tierra el exceso de verbalismo y la falta de experimentación heredada de las etapas históricas anteriores: por una parte, el interés que mostró por el cultivo de determinadas semillas para comprobar el grado de germinación y crecimiento, aprovechando dichas clases para desarrollar contenidos paralelos - idea recogida en los Centros de Interés del pedagogo y médico belga Decroly - como la vida, la luz, la importancia del agua en los seres vivos, las estaciones del año, etc. y, por otra, el destacado intercambio epistolar que realizó entre sus niños y los de otras escuelas nacionales y extranjeras, lo que denota una visión educativa participativa,

\footnotetext{
${ }^{21}$ Expediente personal de Arturo Soriano García. Archivo de la Consejería de Educación. Gobierno de Canarias. Las Palmas de Gran Canaria. Conviene señalar, como aspecto de naturaleza más personal o familiar, que por esta época (1930), se casó con la gran canaria Belén Rodríguez Romero. Fruto de este matrimonio nacerían sus hijos Manuel (1933) y Antonio (1936).
} 
cooperativa e internacionalista que entronca con la pedagogía de Freinet. Conozcamos su propio testimonio a este respecto: "Las cartas que nuestros escolares escribían las vertía yo al francés y traducía a nuestro idioma las contestaciones que recibíamos; enviábamos tubos de semillas, tarjetas postales de paisajes del país y proporcionábamos datos interesantes de nuestras producciones, costumbres, fiestas, etc. recibiendo nosotros de ellos información idéntica" (Memoria personal, p. 6). Incluso, para hacer más interesantes las enseñanzas de Geografía y de otras disciplinas, confeccionaba con los niños una plancha gelatinosa que permitía obtener hasta 100 copias de mapas mudos o de otros contenidos, adaptando al contexto insular el novedoso sistema elaborado en Francia por la Cooperativa Freinet, con la cual, según todos los indicios, se carteaba interesado por su metodología. Un acercamiento temprano al freinetismo, si tenemos en consideración que en 1933 apenas había comenzado a gestarse la Cooperativa Freinet española.

El compromiso adquirido por la teoría -además de la práctica- de la enseñanza, le llevó a participar en numerosos congresos y debates sobre la escuela y los cambios experimentados en la misma. De hecho, el inspector de enseñanza primaria y el director de la Escuela Normal de Maestros de Las Palmas, lo propusieron para asistir a la Universidad Internacional de verano de Santander, con intención de que pudiera participar en los coloquios que se iban a celebrar en torno a la educación; sin embargo, aquel propósito quedó frustrado debido al golpe de Estado que tuvo lugar en julio de 1936.

Un maestro comprometido con la causa republicana como Arturo Soriano, defensor a ultranza de la escuela pública y laica, innovador de contenidos y metodologías y, además, afiliado y militante de la Federación de Trabajadores de la Enseñanza ${ }^{22}$, no podía pasar inadvertido para las autoridades sublevadas que desde los primeros momentos lo depuraron junto a otros compañeros, "por su nociva actuación y actitud antes y con motivo del movimiento nacional salvador"23.

Como parece obvio constatar, fue severamente represaliado. De hecho, el 23 de julio de 1936 fue suspendido provisionalmente de su cargo y apresado por un grupo de falangistas, algunos de cuyos miembros habían sido alumnos suyos en etapas anteriores; tras su detención fue internado en el campo de concentración de Gando con otros destacados defensores de ideas socialistas, como Juan Rodríguez Doreste o Francisco Retana Bonillo. Dicho internamiento y la andanada represiva que se produjo antes, durante y después de aquel hecho, tuvo lugar sin que se hubiera hecho pública y definitiva su separación del servicio docente, a través de la orden ministerial de 24 de abril de $1940^{24}$.

Una vez liberado, en 1941, se trasladó a Madrid donde tenía una hermana y amigos. Allí, durante casi diez años, el tiempo que duró la sanción que lo apartó de la docencia oficial, simultaneó la impartición de clases en el colegio privado Hispano-Francés Príncipe Anglona, con las enseñanzas llevadas a cabo a título particular para poder mantener a su

${ }^{22}$ Su nombre ocupaba el cuarto lugar de un listado en el que aparecían 192 maestros pertenecientes a la Fete, y que fue incautado por el Inspector-jefe con fecha de 11 de noviembre de 1936. Cfr. Relación nominal de afiliados a Trabajadores de la enseñanza que remite el capitán de infantería juez instructor Don Cristóbal García Uzuriaga, en veintisiete de noviembre de mil novecientos treintiseis (sic). Archivo Histórico Provincial de Las Palmas, Gobierno civil, orden público, noviembre de 1936, n. 3.

${ }^{23}$ Relación nominal de afiliados a Trabajadores de la enseñanza que remite el capitán de infantería juez instructor Don Cristóbal García Uzuriaga, en veintisiete de noviembre de mil novecientos treintiseis (sic). Archivo Histórico Provincial de Las Palmas, Gobierno civil, orden público, noviembre de 1936, n. 3.

${ }^{24}$ Información extraída del archivo particular. Hojas sueltas. 
familia. Esta etapa se prolongó hasta que se procedió a la revisión de su expediente y se le habilitó, nuevamente, con fecha de 27 de mayo de 1950, pero fuera de la provincia de origen $^{25}$.

El traslado forzoso lo cumplió en dos escuelas públicas de Madrid; primero, en una de Valdemoro, donde permaneció muy pocos días, y, después, en otra de Barajas. Estando en esta última pudo crear una biblioteca escolar circulante para colaborar en la difusión de la cultura literaria, gestionó el ahorro escolar con cartillas que repartía a los niños a través del Monte de Piedad de Madrid, colaboró con el Padre Luis Medina, fundador de La ciudad de los Muchachos, etc.

Sin embargo, su propósito era regresar lo antes posible a Canarias donde había dejado varios proyectos inconclusos. Así pues, el 1 de septiembre de 1951, tomó posesión como maestro de la sección del Grupo Escolar de Niños de El Puerto de la Cruz, Tenerife ${ }^{26}$. En dicha escuela desempeñó labores de bibliotecario y se convirtió en asiduo colaborador de la revista falangista Escuela Azul, consciente de que de este modo haría más llevadero su particular exilio interior. Con su nombre rubricó a partir de entonces numerosos trabajos sobre la educación, la enseñanza y la cultura; y ello sirvió, entre otras cosas, para que cambiara considerablemente la idea que tenían de él las autoridades ${ }^{27}$ hasta el punto de que el SEM provincial le otorgó su confianza y le comisionó para asuntos relacionados con Canarias. Su trabajo siguió siendo intenso tanto en las escuelas nacionales de El Puerto de la Cruz y La Orotava como en el Colegio de Enseñanzas Medias Gran Poder de Dios, en el que también impartió su docencia en disciplinas como Educación Física y Política. Por esta época creó el ropero escolar con subvenciones del Ministerio y participó activamente en la campaña de alfabetización desarrollada en la Isla ${ }^{28}$.

A partir de 1959, pudo trasladarse al grupo escolar de niños de Las Palmas, Carlos Navarro Ruiz, donde ocupó el cargo de director desde su llegada hasta el momento de su jubilación forzosa, como se denominaba entonces, ocurrida en mayo de 1969. Tanto habían cambiado las cosas, que un año antes de este hecho le fue concedida la Orden Civil de Alfonso $X$ el Sabio "en atención a los servicios de mérito extraordinario prestados en el desempeño de su función de Maestro Nacional"29.

Durante esta última etapa al frente de la escuela, impulsó la labor de la biblioteca escolar, llamada también infantil, tratando de dotarla de la mayor cantidad de libros posibles; puso en práctica, como años antes había hecho en Madrid, la creación de una

${ }^{25}$ Los dos informes más valiosos que favorecieron su absolución fueron los presentados por Joaquín Artiles Santana, Asesor Eclesiástico de Sindicatos de la Provincia de Las Palmas, en el que certificaba "una conducta intachable en su vida privada y profesional en todo el período de tiempo que desempeñó su cargo en esta localidad", además "en su actuación como Maestro se desvivió por la enseñanza"; y el de Germánico Álvarez García, jefe provincial del Servicio Español del Magisterio de Santa Cruz de Tenerife, adscrito a FET y de las Jons, quien certificó que era "militante de este Servicio y colaborador asiduo de nuestro periódico Escuela Azul, a través del cual ha mostrado en todo momento su decidido entusiasmo en favor del Niño y de la Escuela". Los dos informes estaban sellados en distintas fechas del año 1955. Información contenida en el expediente personal de Arturo Soriano García. Archivo de la Consejería de Educación. Gobierno de Canarias, Las Palmas de Gran Canaria.

${ }^{26}$ Hoja de Servicios. Las Palmas de Gran Canaria, 29 mayo 1969.

${ }^{27}$ No olvidemos que por orden de 13 de noviembre de 1956 terminó de cumplir la sanción que se le había impuesto de traslado forzoso fuera de la provincia de origen, y la inhabilitación para ocupar cargo directivo y de confianza.

${ }^{28}$ Datos que siguen siendo extraídos de la Memoria Personal redactada y documentada por D. Arturo Soriano García, cotejados con otras informaciones procedentes de la prensa local.

${ }^{29}$ Escrito enviado por el Ministerio de Educación y Ciencia, y firmado por el subsecretario con fecha de 26 de noviembre de 1968.

Hist. Educ. (Online)

Porto Alegre

v. 20

ก. 50

Set./dez., 2016

p. $157-175$ 
biblioteca escolar circulante, con lo cual volvía a reiterar su apoyo más decidido al establecimiento y dotación de bibliotecas públicas ${ }^{30}$; organizó y participó activamente en varias colonias escolares; aprovechó la visita de insignes educadores a las islas para entrevistarse con ellos ${ }^{31}$, etc.

Además, por esta época dio a conocer en la prensa local sus impresiones sobre temas variados: bibliotecas, analfabetismo, iniciación profesional, valor de lo espiritual, etc. ${ }^{32}$. Es más, incluso abordó cierta vertiente profesional minusvalorada hasta entonces, pero que con el tiempo se convertiría en tema recurrente de la actividad pedagógica: la determinante acción del tutor en el proceso de adquisición de conocimientos y, por tanto, en el ejercicio continuado del aprendizaje. Eso sí, sin confundir la función del maestro con la del tutor, pues, según afirmaba, ésta debía entenderse "como una especie de ayuda que el profesor puede y debe ofrecer al alumno al margen de las obligaciones que como profesor tiene" ${ }^{\text {"3. }}$.

Durante estos últimos años al frente de la escuela, participó en concursos literarios, periodísticos y educativos a nivel estatal, en los que sus trabajos fueron reconocidos y en algún caso hasta premiados. Esta misma experiencia la intentaba fomentar entre sus alumnos, al invitarles a participar en certámenes de Lengua, Geografía o Matemáticas ${ }^{34}$. Son años en los que, igualmente, fomentaba la práctica de las exposiciones escolares, coordinaba reuniones pedagógicas entre distintos docentes, pronunciaba conferencias, reseñaba libros en la prensa local, etc. Sería pertinente incluso, para comprender mejor su afán por educar y su perseverancia por seguir en contacto con los alumnos, conocer parte del discurso que presentó en el acto "multitudinario" (sic) de homenaje que, con motivo de su jubilación, le tributaron sus compañeros en los salones de la Feria del Atlántico de Las Palmas, el 24 de mayo de 196935: "Por ello, casi me atrevo a expresar mi sentimental

\footnotetext{
${ }^{30}$ No fue casualidad que siendo éste su centro de atención preferencial, publicara numerosos trabajos con dicho tema de fondo. Veamos algunas de sus ideas al respecto: "En los pueblos pequeños, la fundación de bibliotecas tiene una trascendencia grande. El nivel cultural de sus habitantes no suele ser muy elevado y aquejados, parte de ellos de un analfabetismo del que, afortunadamente, se van redimiendo; pero de nada les serviría que se les iniciase en los conocimientos instrumentales si después no son remachados con un perfeccionamiento paulatino y constante que al mismo tiempo que consolida nociones adquiridas con premura, desarrollara una afición a la lectura. De ahí la necesidad de la creación de bibliotecas que tuvieran, además, carácter circulante para hacer compatible el trabajo cotidiano con un afán de superación mediante la lectura como medio recreativo y de información científica, literaria y artística que contribuyesen a la educación integral y a la documentación especializada que oriente y perfeccione al adulto en el aspecto profesional". Arsogar: pseudónimo de Arturo Soriano García: Bibliotecas y promoción cultural. La Provincia, Las Palmas de Gran Canaria, 3 de abril de 1970.

${ }^{31}$ Es de destacar la entrevista que tanto nuestro biografiado - por entonces director del Grupo Escolar Carlos Navarro Ruiz de Las Palmas, como ya hemos adelantado - como Francisco Pérez Saavedra, director del Grupo Escolar de El Puerto de la Cruz, mantuvieron con el dr. belga Joseph Lambert, educador e inspector de enseñanza. El Día, 1 mayo 1960.

32 Todos estos trabajos fueron publicados en Diario de Las Palmas: "Trascendencia social de las bibliotecas escolares", el 2 de diciembre de 1960; "Analfabetismo y alfabetización" I y II, el 14 de abril y el 2 de mayo de 1961; "Consideraciones sobre iniciación profesional", el 28 de julio de 1961; y "Valor de lo espiritual”, el 9 de agosto de 1961.

${ }^{33}$ Manuscrito sin fechar, pero que consideramos de finales de los 60 o principios de los 70 .

${ }^{34}$ Entre sus ensayos sería conveniente citar algunos de los más destacados: Las bibliotecas y su importancia en las vida de los pueblos (1966); Ensayo sobre la educación y el desarrollo (1967); Concurso periodístico de exaltación del libro (1970); y Sugerencias sobre matemática escolar tradicional, sin fechar aunque presentado a concurso con motivo del Día del Libro.

35 "Soy un maestro que, oficialmente, ha llegado a la meta; pero aunque parezca paradoja, también soy de los que creen que la edad cronológica no debiera contar para separar a un educador de sus funciones cuando conserva energías morales, físicas e intelectuales para seguir prestando sus servicios, por modestos que sean, si procura mantenerse al día remozándose con la didáctica de nuestro tiempo". Fragmento del discurso de despedida de la escuela, 1969.
}

Hist. Educ. (Online) $\quad$ Porto Alegre

v. 20

ก. 50

Set./dez., 2016

p. $157-175$ 
protesta por esta separación que trataré de suplir en un aspecto no oficial mientras tenga fuerzas para seguir dedicándome a la misión noble por excelencia: la educación de los niños".

A partir de estos momentos, aunque con más tiempo libre y la misma vitalidad, colaboró en los medios de comunicación canarios para opinar y reflexionar sobre determinados asuntos relacionados con la educación y la cultura. En efecto, con su nombre, con el acrónimo de Arsogar, o con el seudónimo de Maximino, continuó rubricando artículos como los que a continuación citamos, a modo de somero botón de muestra: Bibliotecas y promoción cultural, Biblioteca y educación, Gandhi, el poder de la no violencia, Ante el Día del maestro, etc. En ellos quedaba clara su defensa a favor de la cultura popular, de la educación para la paz como impulsora de la integración, y de la importancia adquirida por los docente no sólo ante los escolares sino también ante el conjunto de la sociedad $^{36}$.

Claro defensor y copartícipe de tertulias, empedernido narrador de vivencias y experiencias educativas, amigo de sus amigos y familia de todos aquellos que se consideraban sus parientes, falleció el 25 de marzo de 1996 en la ciudad de Las Palmas de Gran Canaria. De este modo, con casi un siglo de apasionado trabajo a sus espaldas, repleto de satisfacciones pedagógicas, y tan solo 7 meses después de morir su esposa, dejaba un legado profesional y cultural difícil de superar. Y para sus amigos, una auténtica lección de vida como poéticamente nos reveló: El páramo de la vida / se transforma en un edén / cuando florecen en ella / Verdad, Belleza y Bien. / Pero en toda su floresta / la que más aroma da, / la que perfuma el ambiente, / es la flor de la Amistad (Apuntes extraídos de su archivo particular. Hojas sueltas).

\section{Conclusiones}

Aunque no hayamos podido constatar evidencias documentales generalizadas de la práctica escolar freinetista en las escuelas de Canarias, sí hemos podido rastrear aspectos concretos y compromisos personales, que nos llevan a afirmar que las técnicas propuestas por el pedagogo francés tuvieron una presencia anticipada, real y activa en algunas de sus aulas. La correspondencia escolar, el texto libre, el cinema como complemento pedagógico, el cooperativismo, el trabajo autónomo y creativo, la participación vinculante por parte de los alumnos, etc. se convirtieron en instrumentos de actuación y en dinámicas de acción imprescindibles en el apoyo organizativo de algunas escuelas públicas insulares. Pese a todo, insistimos, los resultados de lo investigado no son precisamente los deseados y esperados inicialmente sobre la proliferación de la pedagogía Freinet en Canarias.

Como otros muchos movimientos de renovación pedagógica, los seguidores de Freinet deseaban activar la escuela, apartarla de la rutina memorística -avalada por el siempre presente libro de texto-, y de la pasividad inoperativa de los alumnos. Las técnicas pedagógicas utilizadas no trataban de interponerse entre el niño y la sociedad, sino de facilitar la inserción de éste en la sociedad deseada y posible, de manera más integral, crítica y constructiva, esto es, transformando lo existente. Ofrecer un aprendizaje ameno,

\footnotetext{
${ }^{36}$ Estos trabajos fueron publicados en su mayor parte en el diario La provincia, de Las Palmas de Gran Canaria, el 3 y 10 de abril de 1970 el primero, el 28, 29 y 30 de marzo de 1974 en Diario de Las Palmas el segundo, el 16 de abril de 1981 el tercero, y el 27 de noviembre de 1981 el cuarto. 
real y efectivo fue, en el fondo, el objetivo propuesto por aquellos maestros que no sólo no fueron entendidos, sino que, además, fueron perseguidos y depurados por los golpistas a partir de 1936.

Fue lo ocurrido, entre otros, a Arturo Soriano García: un docente vocacional, con enormes cualidades personales y profesionales, innovador, ajeno a las pocas comodidades educativas existentes y a los radicalismos ideológicos, y comprometido con la escuela y con la sociedad en su conjunto; pues bien, este hombre, y otros muchos con sus mismos valores, fue separado del servicio e internado en un campo de concentración lejos de los niños y de las ilusiones puestas en construir un futuro en libertad, igualdad y compromiso social para todos. Su pasión por Freinet estaba más que justificada porque su Pedagogía no consistía en hablar a los niños para que siguieran los pasos del adulto, sino en darles la palabra para que fueran ellos los que se expresaran en voz alta, clara y sin complejos, "haciendo camino al andar" como diría el gran poeta republicano Antonio Machado; pero los tiempos habían cambiado y las soflamas belicistas obligaban a callar y a volver dócilmente al redil de la credulidad, la intolerancia y la irracionalidad.

\section{Bibliografía}

ACCIÓN SOCIAL, RELIGIÓN, PATRIA, FAMILIA, ORDEN, TRABAJO Y PROPIEDAD. Santa Cruz de La Palma, 31 mayo 1933.

ACCIÓN SOCIAL, RELIGIÓN, PATRIA, FAMILIA, ORDEN, TRABAJO Y PROPIEDAD. Santa Cruz de La Palma, 1 jul. 1933.

BLAT GIMENO, Amparo. El pensamiento de Freinet i el seu.marc històric. Perspectiva Escolar, 280, 1996.

CLAVIJO REDONDO, Miguel Ángel, FERRAZ LORENZO, Manuel; NAVARRO MEDEROS, Juan Francisco. Luis Diego Cuscoy, maestro y teórico de la educación. Tenerife: Instituto de Estudios Canarios, 2009.

COLABORACIÓN. LA IMPRENTA EN LA ESCUELA. Boletín de la Cooperativa española de la técnica Freinet: Barcelona (agosto1935-julio 1936).

COSTA RICO, Antón. D'abord les enfants: Freinet y la educación en España (1926-1975). Santiago: Universidad de Santiago de Compostela, 2010.

DIEGO CUSCOY, Luis. Ensayo de lectura consciente en una escuela rural. Revista de Pedagogía, 135, Madrid, marzo, 1933a.

DIEGO CUSCOY, Luis. La escuela rural: un ensayo y un ensayo de escuela rural. In: La Prensa, Diario de la mañana. Santa Cruz de Tenerife, 17 y 18 de mayo de 1933.

DIEGO CUSCOY, Luis: Un essai de lecture consciente dans une école rurale espagnole. L'éducateur Prolétarien, 8, Mai, 1933b, Editions de L'impremerie a L'Ecole, Saint-Paul (Alpes Maritimes). También puede verse en <http//www.icem-freinet.fr/archives/ep>.

ERRICO, Gemma. La pedagogía Freinet en España: la importancia del Movimiento Cooperativo de Escuela Popular (MCEP). Cabás, 12, 2014, p. 1-14.

FERRAZ LORENZO, Manuel. Luis Diego Cuscoy: maestro y arqueólogo. ¿Defensor de las técnicas educativas de Freinet durante los años 30?, p. 325-334. In: CELADA PERANDONES, Pablo. Arte y oficio de enseñar: dos siglos de perspectiva histórica. Burgo de Osma: Sedhe/Universidad de Valladolid y Centro Internacional de Cultura Escolar, 2011. 
FERRAZ LORENZO, Manuel; GONZÁLEZ DELGADO, Mariano. Julian B. Caparrós Morata (1908-1988): un ejemplo exigente de renovación educativa antes, durante y después de la transición democrática, en prensa, 2016.

FREINET, Célestin. Tecnicas Freinet de la escuela moderna Madrid: Siglo XXI, 1969. (edición original francesa, 1964).

GONZÁLEZ-MONTEAGUDO, José. Célestin Freinet, la escritura en libertad y el periódico escolar: un modelo de innovación educativa en la primera mitad del siglo 20. Hist. Educ. (Online), Porto Alegre, v. 20, n. 40, 2013, p. 11-26.

HERNÁNDEZ DÍAZ, José María; HERNÁNDEZ HUERTA, José Luis. Bosquejo histórico del movimiento Freinet en España (1926-1939). Foro de Educación, n. 9, 2007, p. 169-202.

HERNÁNDEZ HUERTA, José Luis; HERNÁNDEZ DÍAZ, José María. Freinet en España (1926-1936). Hist. Educ. (Online), Porto Alegre, v. 16, n. 36, 2012, p. 11-44.

HERNÁNDEZ HUERTA, José Luis. La influencia de Celestin Freinet en España durante la década de 1930: maestros, escuelas y cuadernos escolares. Salamanca: Anthema, 2005.

HERNÁNDEZ HUERTA, José Luis. La Escuela moderna en España. Primera época (1929-1936). In: SÁNCHEZ, Felicidad.; ALEJO, Francisco Javier; CALVO, Gaspar; LUCERO, Manuel; GONZÁLEZ, María Paz; ORIA, María Rosa e IGLESIAS, Enrique: Relaciones internacionales en la Historia de la Educación: Junta para la Ampliación de Estudios e Investigaciones Científicas (1907-2007). COLOQUIO NACIONAL DE HISTORIA DE LA EDUCACIÓN, 14, 2007, Guadalupe (Cáceres): Sedhe/Departamento de Ciencias de la Educación de la Universidad de Extremadura, 2007.

IMBERNÓN MUÑOZ, Francisco. Célestin Freinet y la cooperación educativa. In: TRILLA, Jaume. El legado pedagógico del siglo XX para la escuela del siglo XXI. Barcelona: Grao, 2009, p. 249-270.

JIMÉNEZ MIER TERÁN, Fernando. Un maestro singular: vida, pensamiento y obra de José México: Tapia, 1989.

JIMÉNEZ MIER TERÁN, Fernando. Seis experiencias de educación Freinet en Cataluña antes de 1939. Madrid: Aula Libre, 1994

JIMÉNEZ MIER TERÁN, Fernando. Freinet en España. Colaboración, Barcelona, 1996.

JIMÉNEZ MIER TERÁN, Fernando. ¡Viva la imprenta! Orígenes de la educación Freinet en España. Libro de Vida. México: Tanteo, 2011.

JIMÉNEZ MIER; TERÁN, Fernando. Nacimiento y vísperas de la Cooperativa. In: Págines vives. Quaderns Freinet. Les revistes escolars de la segona república. Universitat Jaume I: Castelló de la Plana, pp. 156-157, 2012.

LA IMPRENTA EN LA ESCUELA. Boletín de la Cooperativa de la técnica Freinet. Barcelona (marzo-julio 1935).

MOVIMIENTO COOPERATIVO DE ESCUELA POPULAR. La escuela moderna en España. Zero ZYX: Madrid, 1979.

RAMOS, Alfred. Mestres de la imprenta: el moviment Freinet valencià (1931-1939). Alicante: Fundació Soler i Godes/Universitat Jaume I, 2016.

ZURRIAGA, Ferrán. La segunda época de la experiencia Freinet en España. In: La escuela moderna en España: movimiento cooperativo de escuela popular. Bilbao: Zero-ZYX, 1979. 
MANUEL FERRAZ LORENZO es profesor titular de Teoría e Historia de la Educación en la Universidad de La Laguna, España.

Dirección: Ctra. General del Norte, 419 - Los Naranjeros - CP38350 - Tacoronte Tenerife - España.

E-mail: mferraz@ull.es.

Recebido em 28 de abril de 2016.

Aceito em 1으 de julho de 2016. 